\title{
Metadesign e Sustentabilidade em Redes: Complexidade e construção de sentido
}

MENDONÇA, Bárbara Rangel de Carvalho Braga de Mendonça; Programa de Pós Graduação da Escola de Design, Universidade do Estado de Minas Gerais - UEMG

barbarademendonca@gmail.com

NEVES, Dimitri Bassani Santos; Programa de Pós Graduação da Escola de Design, Universidade do Estado de Minas Gerais - UEMG

dimitribsn@gmail.com

Palavras-Chave: metadesign, co-design, design estratégico, redes, sustentabilidade.

Resumo: Desde que a sustentabilidade passou a compor pautas de discussão internacionais, tornouse necessário reavaliar os fundamentos e o papel do design. Este artigo discute o metadesign como caminho para a sustentabilidade, promovendo a descentralização do especialista em design rumo à inclusão de diversos atores em comunidades criativas. Propõe ainda o modelo de organização em rede distribuída como viés, potencializado pelos meios digitais de estruturação social. Aborda portanto as redes por duas óticas distintas (mas associáveis): enquanto fenômeno social de articulação de atores acerca de um objetivo comum; e como tecnologia de informação e comunicação - a internet. $E$ problematiza-se: A dificuldade de conciliar o metadesign e sustentabilidade na rede poderia auxiliar a participação em rede para inovação social? Primeiramente é abordada a materialização dos conceitos apresentados, e a partir de um exemplo ilustrativo foi realizada uma avaliação na ótica do design metaprojetual e design estratégico para validar a discussão.

Key-words: metadesign, co-design, strategic design, networks, sustainability. 


\section{Introdução}

Desde que a sustentabilidade passou a compor pautas de discussão internacionais, tornouse necessário reavaliar os fundamentos e o papel do design. Seu domínio precisou transcender as características estéticas e funcionais do produto que ocasionaram seu surgimento. Isto porque o modelo consumista vigente, promovido e sustentado pelas economias dominantes, provou-se insustentável e evidencia a marcha para um cenário catastrófico iminente - já verificável globalmente nas economias produtivas mais impactadas, não apenas nos quesitos econômico e ambiental, mas principalmente sociocultural. Como reflexo, verifica-se a manifestação recorrente de uma busca por soluções alternativas partindo das populações mesmas, ou como para Manzini (2008, p.17) grupos de pessoas inventando espontaneamente novos modos de viver sustentáveis.

Neste sentido, as novas dimensões do design para a sustentabilidade discutido por Manzini e Vezzoli (2002, p. 10) e Vezzoli (2007, p. 50) incluem a melhoria ambiental de fluxos de processos e operações; o redesenho ambiental do existente e o design de novos produtos ou serviços intrinsecamente sustentáveis; mas principalmente, propõem sistemas de inovação - cenários que promovam o consumo suficiente; ferramentas e métodos do design para equidade e coesão social, campo no qual, segundo eles "o design tem buscado compreender as implicações da dimensão social da sustentabilidade em suas atividades projetuais".

Concomitantemente, Silva et al (2015) destacam o consumo sustentável; a coesão social e a valorização dos recursos locais, e defendem um design voltado para a equidade e coesão social que, juntamente com os stakeholders, começa a se articular para enfrentar questões econômicas, ambientais, culturais e sócio-éticas, através de um pensamento global e sistêmico que, no cenário atual, deverá permear a concepção do projeto como um todo.

Enquanto para Vezzoli (2007), a transição para uma sociedade sustentável requer um amplo processo coletivo de aprendizagem em que, além do designer, cada ator social desempenhe seu papel, capacitando-se e assumindo uma atuação significativa e responsável.

O conjunto exposto aponta para o metadesign como abordagem mais atual, posto que enseja, na concepção de Franzato (2014) e de Giaccardi (2005), o envolvimento dos demais atores no ecossistema criativo, constituindo uma rede de ativos humanos e não humanos em que os interesses das partes criam a coesão e envolvimento necessários à projeção do novo cenário.

Este artigo discute o metadesign como caminho para a sustentabilidade, promovendo a descentralização do especialista em design rumo à inclusão de diversos atores em comunidades criativas. Propõe ainda o modelo de organização em rede distribuída como viés, potencializado pelos meios digitais de estruturação social. Aborda portanto as redes por duas óticas distintas (mas associáveis): enquanto fenômeno social de articulação de atores acerca de um objetivo comum; e como Tecnologia de Informação e Comunicação (TIC).

\section{Problematização}

A busca por ressignificar o papel do design rumo a uma sustentabilidade que envolva redes de atores autônomos, empenhados por motivações próprias, vai ao encontro de algumas das definições do metadesign. De acordo com Santos (2009), o momento metodológico deve ser a instrumentalização, ou seja, a apropriação dos instrumentos teóricos e práticos, necessários ao equacionamento do problema detectado na prática social. A consideração de agentes com diferentes saberes, como um movimento de articulação no processo metodológico criativo de cenários participativos, contribui para o projeto em parceria e, assim, melhores formas de propulsões sociais.

No panorama urbano, presenciamos áreas de regionalização demarcadas por projetos de interesses governamentais na coordenação das secretarias de planejamento urbano, algumas vezes quebrando o paradigma unilateral de elaboração dos planos para orientar projetos participativos em nível municipal. Dessas experiências consideram-se ferramentas e plataformas digitais, governamentais ou particulares, que permitem seus usuários atribuir registros dinâmicos na forma de dados georreferenciados, ou seja, geograficamente localizados sobre um mapa digital. Nesse sentido todos os interessados em contribuir para sanar pro- 
blemas urbanos reais ou se envolver na projetação de soluções sociais poderiam tornar-se agentes potenciais na compreensão de como os eventos podem influenciar os processos de ocupação e transformação das cidades. Como anotado por Nascimento (2015), não se limitando apenas a arquitetos e planejadores urbanos.

O metadesign como investigação metodológica poderia integrar-se aos demais modelos de projetação desenvolvidos a cenários sociais em redes distribuídas? Para validar a discussão são analisados os conceitos de metadesign, sistemas de redes, codesign, Internet, design estratégico, cenários participativos e empoderamento. A investigação da aplicação cartográfica como representação digital nesse processo metodológico é ilustrado ao fim.

\section{Metadesign}

Krippendorff (2006) propõe que o metadesign suporta indivíduos "construírem sentidos". Para Franzato (2014) o processo metaprojetual está num nível diverso do processo do design, não representando meramente uma de suas etapas. Giaccardi (2005) agrega que ele assume um processo próprio, com espaços abertos para interação criativa entre co-designers. Esta concepção fundamentada em uma rede colaborativa é diversa daquelas defendidas por outros autores, e será a utilizada nesta abordagem.

Entendido enquanto projeção de cenários possíveis, o metadesign orienta redes participativas a fim de viabilizar soluções sistêmicas que se baseiam na teoria da complexidade. Giaccardi (2005:348) propõe que o designer deixe de "planejar" e controlar todos os desdobramentos do projeto para "semear" práticas colaborativas e transformacionais que possibilitem novos modos de interação humana e proporcionem a expansão do processo criativo, como reforçado por Brunel (2015) seja entre designer em um projeto de design voltado a desenvolver sistemas produto-serviço para o mercado, ou entre diferentes atores em um processo de co-design de inovação social.

Não apenas experts em design, mas também não designers são admitidos entre os atores. Conforme lemos em Franzato (2014b:95), o designer deverá atuar como facilitador do codesign promovendo:

[...] um software que possibilite usuários projetarem, um serviço de crowd-sourcing que facilite a convergência de diferentes expertises, um ambiente que permita formas coletivas de trabalho, um toolkit que encoraje o desenvolvimento de processos de design onde não existam habilidades de design, uma infra-estrutura sociotécnica que estabeleça as bases para o open design, e assim por diante.

Portanto, um modelo projetual que funciona a exemplo das iniciativas anteriormente descritas por Manzini (2003), na busca espontânea por "novos modos de viver sustentáveis". Essas redes não devem ser compreendidas meramente como estruturas hierárquicas ou conexões, ainda que descentralizadas. Precisam estar niveladas horizontalmente a fim de promover equidade e comprometimento autônomo.

\section{Redes}

Martinho (2013) propõe substituir a hierarquia pela "dinâmica horizontal que a rede proporciona", potencializando a emergência de novos valores, fomentando inovação e criatividade ao reunir atores diferentes com objetivos comuns. É neste sentido que destacamos diferentes articulações em rede apontadas por Baran (1964), na figura 1.

Onde em tais articulações, ilustradas na Figura 1, podem ser comparadas a rede de tipo centralizada $(A)$ da qual é vulnerável por se articular sobre um único ponto; enquanto a rede descentralizada (B) se articula em pontos múltiplos estratégicos, fortalecendo a comunicação. Mas é na rede distribuída (C) que se verificam fluxos autônomos, possibilitando um sistema dinâmico e que leve em conta os potenciais de cada ator envolvido. Neste modelo o designer assume papel de mediador, articulando estruturas sociais e estimulando soluções inovadoras. 

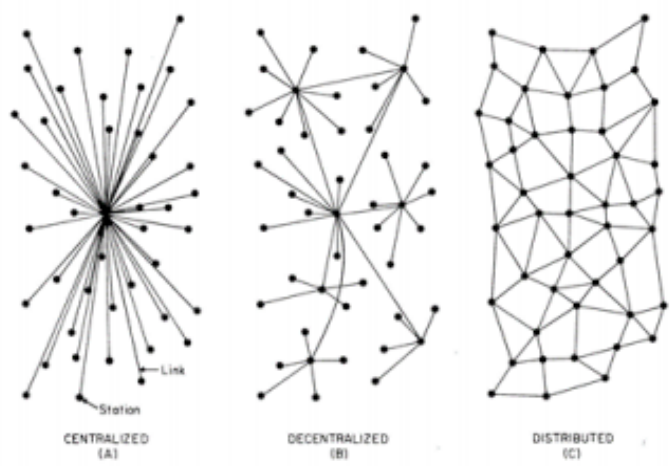

Figura 1: Representação de rede centralizada, descentralizada e distribuída. Fonte: Paul Baran (1964)

É visivelmente a estrutura que melhor define o momento atual, com as agremiações espontâneas que se formam em torno de interesses e objetivos comuns, inclusive via redes sociais na internet. Não respondem a hierarquias e, segundo Deleuze e Guattari (2007) nela os atores têm liberdade para associarem-se, reassociarem-se ou aderirem a outros coletivos, sendo portanto, sempre acêntricas ou rizomáticas. Como em Eichenberg (2014):

Dentre as capacidades consideradas pertinentes nesse processo percebe-se o posicionamento ativo dos indivíduos como sendo a mais relevante delas. Isso se deve ao entendimento de que é essa autonomia, somada ao compartilhamento das especificidades percebidas por cada indivíduo, que origina os aspectos necessários para a articulação de um sistema social aberto e complexo

O designer abre mão de um papel central para atuar nas articulações de um sistema complexo. Seu papel deixa de ser centralizador, agregando conhecimentos para gerar uma solução universal - ou o "paradigma da simplificação" amplamente adotado pela lógica científica, conforme apontado por Morin (2002), que defende um "paradigma da complexidade" em que a multiplicidade é preservada e pode manifestar sua força, que vai além das capacidades individuais somadas.

\section{Co-design}

O designer deixa de se empenhar por produzir uma solução de design para possibilitar meios para que o design aconteça. Em projetos de design coletivo, pessoas envolvidas no problema passam a fazer parte também da solução. De acordo com Manzini (2014:23) as tradicionais fronteiras entre designer, provedor e usuário de uma solução tornam-se cada vez mais turvas. Não existe o perfil estereotipado de participantes. Esta visão com características de auto sustentabilidade investe o designer da tarefa de municiar de ferramentas projetuais os atores de comunidades surgidas em torno de um problema comum. Manzini (2003; 2014) defende ainda que o conhecimento em design, frequentemente difuso e não intencional, muitas vezes não está formalizado no papel de um expert em design, o que pode ser verificado no caso da inovação social. O mesmo autor (2014:58) completa que:

Para promover a inovação social, experts em design devem usar suas habilidades e competências em design para reconhecer casos promissores quando e onde eles surgem e reforçá-los. Que é ajuda-los a ser mais acessíveis, efetivos, duradouros e replicáveis.

Não se trata portanto de reunir todas as competências necessárias para solucionar um problema, mas de saber encontrar tais competências entre os atores envolvidos, e extrair deles a oportuna participação. Isto pode ser bastante desafiador em um contexto em que a virtualidade passa a ser a modalidade predominante de convívio social. Ao mesmo tempo, nunca a tecnologia de comunicação reuniu tantas pessoas conectadas em tempo-real. 


\section{Internet}

Este fenômeno mundial marcou indelevelmente a sociedade contemporânea. Suas potencialidades para a inovação social vêm sendo exploradas, mas há ainda muito campo para a atuação do designer no viés do metaprojeto e do co-design. Para Castells (2006) é chamado de mass-self communication, onde os processos massivos com fluxos informacionais centralizados e pós massivos, podem ser customizados para produzir, armazenar e circular informações sob vários formatos e modulações em qualquer ponto de acesso. Problemas globais jamais estiveram ao alcance de comunidades tão vastamente amplas, aguardando sua mobilização para proposição de soluções. E quem, senão o designer, melhor poderia propor tais mobilizações? Lipovetsky (2004) diz:

ao possibilitar o acesso a uma informação cada vez mais diversificada e mais caracterizada por pontos de vista diferentes, [...] a mídia permitiu que se desse aos indivíduos maior autonomia de pensamento e de ação, com a oportunidade de constituir opinião própria sobre um número sempre maior de fenômenos.

Resta então capacitar o designer com uma metodologia capaz de aglutinar tais indivíduos em torno de grandes causas comuns. Neste sentido, Lastres et al (2002) defende que Tecnologias da Informação e Comunicação (TIC) impulsionam um conjunto de inovações técnico-científicas, organizacionais, sociais e institucionais e geram novas possibilidades de retorno econômico e social. As TIC se referem a todas as possibilidades tecnológicas tratadas por fios, cabos, ou sem fio, se estendendo à inclusão digital. Presenciam-se interações diárias das mais diversas formas que transformam as relações humanas com as tecnologias digitais e deste cenário foram disseminadas várias ferramentas de mapeamento digital e contribuições de produção temáticas colaborativas para divulgação de informações.

Nos ensaios propostos por Raquel Daroda (2016), as TIC são capazes de favorecer a interação entre o homem e o espaço urbano, porque contribuem para novas formas de descoberta desses espaços, bem como para a formação da sua história, sendo por isso parte constituinte do perfil do usuário da cidade do século XXI.

\section{Design estratégico (DE)}

O Design Estratégico (DE) pode, reforçar a dimensão mais complexa em que o metadesign se estabelece. Manzini (2003:233) afirma que este, "por definição, lida com artefatos complexos (...) Toda solução e, especialmente, soluções sustentáveis trazem um sistema de relacionamento que lida com novas formas de colaboração entre vários atores e/ou interessados". O DE lida não mais com artefatos triviais ou máquinas que podem ser controladas, mas com organizações, no projeto coletivo da estratégia e, portanto, segundo Mauri 1996), com sujeitos e seus ecossistemas. Por isso, Brunel (2015:6) está embrenhado em um universo mais complexo do que o que outrora era compreendido como espaço do design. Entende-se assim que o DE, com suas habilidades e capacidades, pode atuar orientando as conversações sociais e o processo de design para sustentabilidade. Mauri (1996) traz a concepção do projeto da estratégia como um projeto coletivo, transdisciplinar, em que considera o sujeito trans-pessoal que não soma individualidades, mas sim produz coletivamente uma nova forma de inteligência. Segundo Magalhães (1995, p.26) é mais importante do que desenvolver corretamente o produto, com eficiência no processo de design, materializar - DE pela eficácia de ferramentas e recursos de design que possam ser propostas e promovidas no processo de design. Sendo assim, concebidos e cujo foco está na identificação e criação destas condições a partir de nível decisório mais alto dentro destas e desde fases do desenvolvimento de produtos, com todas as áreas relevantes, segundo MagaIhães(1995) e Best (2006).

Dentre os recursos que costumam ser mais empregados pelo DE, Meroni (2008:35) afirma que "cenários são visões compartilhadas que traduzem informações e intuições em conhecimentos perceptível". Este autor traz a concepção de cenários orientados pelo design: "conjunto de visões motivadas e articuladas, que visam catalisar as energias dos diversos atores envolvidos no processo de design, para gerar uma visão comum e desejavelmente orientar suas ações na mesma direção". 


\section{Cenários}

Os cenários são uma atividade do design, usados para suportar processos projetuais, produzindo sobretudo, metadesign. Zurlo (2010) destaca que a explicitação de um modelo de entendimento por todos os atores (internos e externos) de uma organização, através da facilitação dos processos de interpretação, se dá para o design na eficácia da comunicação e no compartilhamento desse entendimento. Segundo a teoria de Gordon Park, a teoria de conversação se dá pela possibilidade de criar um debate dialógico entre os participantes individuais: a construção de sentido ocorre a partir da troca recursiva e da comparação mútua das interpretações de cada parte sobre o objeto em discussão. Sendo assim, Brunel (2015; apud PASK apud GLANVILLE, p. 19, trad.livre. 54) aponta que é crucial o entendimento da construção de significados pelos participantes, pois distingue a conversação da simples transmissão de conteúdos codificados.

\section{Organizações colaborativas}

Segundo Brunel (2015), às organizações colaborativas impõe-se a criação de um novo cenário de operações de design - que possa sustentar ecossistemas criativos - tornando-se apropriada a abordagem do DE. O ecossistema criativo, de que fala Franzato (2014), trata de um ecossistema sociocultural que é caracterizado "pelo desenvolvimento de processos criativos que resultam em dispositivos sócio-técnicos (artefatos, processos ou sistema), possivelmente originais e inovadores". E nesse sentido, o DE poderia reforçar a complexidade em que o projeto de design se estabelece. Manzini (2003) define o DE como a atividade que lida com artefatos complexos (...) e, especialmente, todas as soluções sustentáveis trazem um sistema de relacionamento que lida com novas formas de colaboração entre vários atores e/ou interessados".

\section{Cartografia}

As representações cartográficas, apesar de muito antigas, tinham sua importância estrita como meio de localização e conhecimento do território. Segundo Ferreira (2007), após o processo de globalização houve uma mudança nas concepções sobre educação e o reconhecimento da importância da cartografia para diversas áreas do conhecimento se tornou pauta de discussões em muitos congressos de caráter nacional e internacional. Este fato pode ser demonstrado pelo recente uso de mapas digitais pela população (SILVA, 2014). Hoje em dia, o aplicativo do Google Maps já vem instalado nos dispositivos móveis para Android e Apple, que em 2011 representavam $40 \%$ do uso de todos os mapas. Ao longo do tempo foram incorporadas novas formas de representação cartográfica, classificado como cartografia temática (MOURA, 1993).

Como muito abordado, Milton Santos dizia que o território é o espaço socialmente construído. O espaço se tornou uma variável fundamental na nova percepção de mundo, atribuindo às análises espaciais uma ferramenta para a obtenção de diagnósticos ambientais e urbanos. Principalmente a partir do desenvolvimento das geotecnologias, deve-se considerar que sua difusão foi permitida em função da facilidade de procedimentos realizados (FERREIRA, 2007).

Diferentes tipos de cartografias digitais são lançadas constantemente no mundo digital - em aplicativos e sites - providos pelo poder público, mas principalmente por iniciativas da sociedade civil - em mapas digitais independentes - que em sua maioria funcionam em uma vertente colaborativa. Silva (2014) analisou que dentre as funções propostas pelo mapeamento, a cartografia temática voltada para desenvolvimento e melhoria da cidade recebeu a maior frequência em 150 casos de mapeamento coletados. Incluindo exemplos de mapeamentos que visam a mobilidade urbana, a denúncia de problemas em determinadas regiões, a facilidade nas relações entre clientes e serviços (como chegar ao cinema, como chegar ao restaurante), entre outros aspectos. Nesse sentido, Silva (2014) destaca a necessidade de criação de micro redes de ações colaborativas capazes de enriquecer o conteúdo mapeado a partir de comentários, compartilhamento de fotos e vídeos, e a possibilidade de seguir pessoas, integrando-se a outras mídias sociais e assim por diante. Ou seja, a partir 
da produção e diálogo entre os atores desse ecossistema colaborativo, são determinadas as características de uma determinada organização temática, e assim, a transfiguração digital de lugares de reconhecimento dos comuns.

A possibilidade de mapeamentos temáticos se tornou uma maneira de criar um canal aberto na construção coletiva de políticas e gestão espacial. O mapeamento digital temático propicia um ambiente digital para divulgação e gestão de ativos a exemplo da cultural, e outras ferramentas como a de orçamento participativo, que podem ser rotina de consulta e interação do cidadão com outros agentes. No viés das redes, o mapeamento cultural facilita a descentralização ao gerar aos seus colaboradores feedbacks re-avaliativos, alternando prática e reflexão crítica, e quem sabe, surtindo de forma espontânea e orgânica atividades de força tarefa específicas aos locais de análise.

A realidade híbrida dos espaços virtuais e físicos dos ambientes urbanos se torna reconhecida a partir do programa $\mathrm{BH}$ Digital, proveniente de recursos governamentais, e organizado pela PRODABEL - Empresa de Informação e Informática do Município de Belo Horizonte S/A. O programa realiza ações localizadas em pontos de acesso público, como praças dos bairros e parques da cidade de Belo Horizonte e tem como objetivo, segundo o Portal $\mathrm{BH}$ (2016), ampliar a disponibilização de acesso gratuito à Internet nas vilas, favelas e praças de Belo Horizonte e avançar na integração dos municípios conurbados à Capital por meio da conexão destes à rede de Internet da $\mathrm{PBH}$.

A exemplo de ilustração de um problema mal estruturado por organizações constituídas no ambiente digital, que reproduz os questionamentos de um contexto complexo, pode-se citar o projeto Mapa Cultural de Belo Horizonte. O projeto é o mapeamento temático georeferenciado de eventos culturais, desenvolvido pela Fundação Municipal de Cultura (FMC), da Prefeitura de Belo Horizonte (2016), utilizando softwares livres, e essencialmente baseado no conceito de participação de atividades em rede. O intuito é promover uma plataforma online gratuita, com diversas informações sobre o cenário cultural da cidade de Belo Horizonte. O mapa, que pode ser visto na Figura 2, foi construído para abrir espaço de interação da população, sendo uma forma de analisar as suas contribuições culturais para medir sua aceitação. A plataforma é alimentada por dois tipos de usuários: a FMC com informações sobre os espaços culturais, programações oficiais, projetos e editais; e pela população em geral, que se cadastra como agente (individual ou coletivo) e pode divulgar suas próprias programações. Dessa forma é possível para a Fundação Municipal de Cultura coletar dados, gerar mapas e relatórios que ajudarão no planejamento de políticas culturais, e a ferramenta também propõe-se auxiliar na divulgação da agenda de eventos e na memória das atividades.

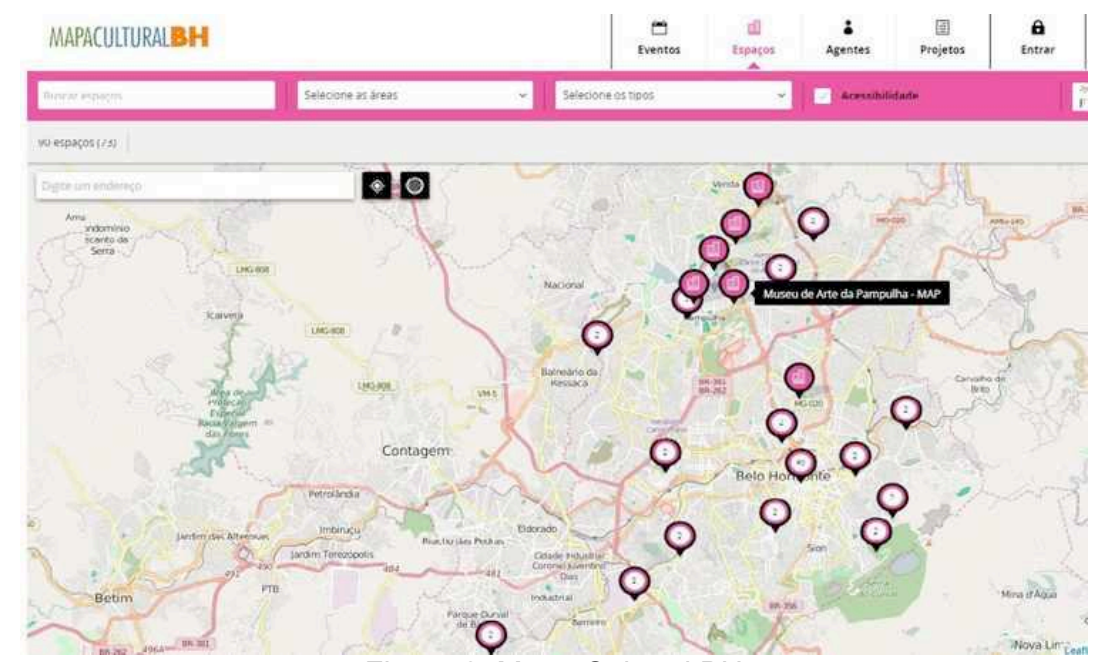

Figura 2: Mapa Cultural BH

O projeto está alinhado com o Sistema Nacional de Informações e Indicadores Culturais (SNIIC) do Ministério da Cultura, apresentado pelo BH Faz Cultura (2016), garantindo nacionalmente assim, a integração e a visualização das informações culturais. De acordo com o IBGE (2012), 143 destes pontos estão em São Paulo (a partir do Programa WiFi Livre SP), 77 em Minas Gerais (BH Digital) e 69 no Rio Grande do Sul. Das 744 cidades brasileiras

\section{UFPEL}


contempladas até 2013, de acordo com o IBGE (2012), apenas 141 têm cobertura em toda área urbana, sendo que $92 \%$ dessas cidades tem menos de 50 mil habitantes.

No entanto a adesão ao uso pela população é um processo orgânico, que por sua vez iniciou-se em 2014 a partir de um projeto desenvolvido pelo grupo de Pesquisa intitulado Indiscipliar, da Escola de Arquitetura e Design da UFMG, financiado pelo CNPq (Conselho Nacional de Pesquisa), MinC (Ministério da Cultura) e SEC (Secretaria de Economia Criativa). O projeto Cartografias emergentes: a distribuição territorial da produção cultural em Belo Horizonte criou um abrangente mapeamento contemplando muitas manifestações culturais e artísticas, para além dos equipamentos oficiais, práticas auto-organizadas, efêmeras ou de escala local para dar visibilidade a ações acadêmicas e ativistas, evidenciadas com o respaldo acadêmico para buscar oportunidades mais justas de captação de recursos e de apoio voltados ao incentivo à cultura.

Diante dos conceitos apresentados, a pesquisa admite conceitualmente, que podem ser criados ecossistemas criativos a partir da instalação de projetos que forem pensados para ser relacionados ao cotidiano comportamental dos espaços de mapeamento geo-referenciado. Para isso os projetos devem ser norteados pelo modelo apresentado pelo metadesign. Afinal a cartografia e mapeamento temático fazem anotações de um espaço existente mas potencialmente podem ajudar a criar novos cenários de entendimentos, usos, práticas colaborativas e conhecimentos tácitos sobre a cidade. Conforme os pressupostos abordados, mesmo que inferindo a participação de designers na concepção do projeto, sendo este o resultado associativo dos diversos atores - incluindo governo, sociedade civil e representantes dos grupos de interesse - a plataforma nos faz refletir sobre as aproximações epistemológicas dos termos de sistemas sociais e digitais. Uma vez que para Castells(1999, p.43), a tecnologia é a sociedade, e a sociedade não pode ser entendida ou representada sem suas ferramentas tecnológicas. As redes de comunicação foram tão evoluídas e são tão necessárias quanto às necessidades da sociedade, que dão forma a tais novas tecnologias globalmente, superando fronteiras à comunidade digital. Ou seja, Martinho (2013) elucida que se a tecnologia possibilitou que a comunicação ocorresse por ferramentas gratuitas, intuitivas e de fácil utilização, são os atores sociais que para gerar transformações disruptivas, devem sentir a necessidade de participar do movimento, deixando de ter uma atitude passiva na recepção das mensagens, para uma atitude participativa.

Pelo fato da realização do estudo dos fatores que possam gerar impacto sobre resultados das deliberações participativas entre cidadãos, dentro das configurações de utilização das TIC's, Sampaio (et. al, 2010) destaca a escassez de reflexividade e reciprocidade nos espaços discursivos analisados por ele, "entretanto, o respeito pelos outros interlocutores, bem como a construção da justificativa dos pontos de vista expressos no fórum, alcançaram índices elevados, mesmo sem familiarização com a ferramenta ou incentivo por parte da Prefeitura". Nesse sentido, a capacidade de participação dos usuários pode ser discutida quanto a maneira de distribuição que os dados são registrados, de modo a abrir uma sequência de descrições similares, e a capacidade de atividades de registros possibilitadas nos mesmos - tornando o caráter qualitativo dos mecanismos de participação mais ou menos deliberativo".

Abranches (2013), no estudo de caso de caso de Belo Horizonte apresenta a verificação das dinâmicas e resultados do funcionamento dos conselhos municipais na elaboração de um perfil sócio-demográfico dos conselheiros municipais. E afirma que não deveria haver incoerência entre a indicação dos conselheiros dos bairros, que deveriam utilizar as plataformas de mapeamento colaborativo temático para levantar os problemas emergentes como no caso das Operações Participativas. Ainda segundo a autora, o atendimento prioritário das anotações geo-referenciadas seria uma ferramenta ordenada de modo a receber investimento público direcionado para a resolução dos fatores apresentados. No entanto, o autor ainda ressalta que dificilmente o uso das TIC trará flexibilidade metodológica nos casos de Gestão pública dito que em algumas experiência analisados, muitos são os casos onde o uso das TIC não determina novas configurações híbridas, mas tende apenas a reforçar a linha interpretativa principal de expor cada experiência.

Partindo desses pressupostos, para que conhecidos os métodos de processamento efetivos de aprendizado e amadurecimento político para constituição de uma participação efetivamente qualitativa no âmbito digital, percebe-se a oportunidade de integrar conhecimentos 
entre os campos das TIC e Design Estratégico (DE). Fazer com que as tecnologias sociais resultantes de esforços de pesquisa sejam implementados nos planos de gestão pública sem o alcance de padrões mercadológicos requer sua integração a metodologias capazes de promover o incremento de desempenho, adaptações de uso e ampliação da participação democrática. E nesse sentido, o processo de DE pode devolver o caráter democrático aos instrumentos de mapeamento geo-referenciado para oferecer mais embasamentos para os cidadãos na tomada de decisões sobre seus registros digitais.

\section{Conclusão}

Portanto, sugere-se a incorporação do Metadesign como um processo, e do Design Estratégico como campo de conhecimento necessário à orientação e ao planejamento da participação digital, de modo que se possa estabelecer o direcionamento e coordenação de métodos de design e suas especificidades durante as diferentes fases de coleta de dados nos exercícios de colaboração deliberativa em redes distribuídas.

Seguido por uma discussão crítica, a provocação que se defende é a importância da integração entre TIC e o projeto de Metadesign nos cenários urbanos, para servir a estes mecanismos na estruturação e gerenciamento de informações de seus resultados internos de desenvolvimento de propostas de qualificação espacial, e ao mesmo tempo, à adequação aos interesses participativos em que se pretende inserir as ferramentas de DE desenvolvidas. Entende-se que essa integração auxilia a desenvolver ferramentas melhores, a difundir e promover modelos metodológicos e a alcançar resultados sustentáveis aos ambientes públicos, para que efetivamente contribuam para o desenvolvimento econômico, social e cultural local que potencializa cada ator envolvido.

A complexidade de tais articulações digitais está em não verificar somente o modelo distribuído dos atores envolvidos no sistema social, mas em como articular tais estruturas para estimular o interesse de atuação dos mesmos; Nesse sentido, destacam-se como apontamentos, a oportunidade de: auxiliar como que se organizem em redes ou se reorganizem utilizando o meio digital; tornar esta interação prazerosa e facilitada tanto quanto possível a fim de amplificar a pervasividade das informações que comporta são desafios que o designer deverá abordar sempre integrando-se aos co-participantes da rede em que se insere como um igual, horizontalmente; essas são tarefas complexas que demandam uma abordagem eficiente em tal contexto. Considerando também a capacidade de articulação para interferir tais propostas na organização dos desenvolvedores das instituições, ou no panorama de suas próprias vidas; e por isso, como seria então, na condição de manterem o interesse dos atores usuários do grupo adepto ao movimento. Também podem ser considerados a necessidade de estimular o reconhecimento às questões locais, que demandam de tal articulação, para que seja possível se inserir em um processo já demandado pelos cidadãos, estando conscientes deste fato ou não. Para De Moraes (2010), o metaprojeto considera o cenário e o território fluídos e dinâmicos, nos quais atua uma pluralidade de atores sociais com papéis diferentes e mutáveis. Lipovetksy (2008), ressalta que:

O fato é que a lógica binária de nossas sociedades seguirá ampliandose e que a responsabilidade de cada um ganhará cada vez mais importância. Nenhuma outra sociedade jamais possibilitou que se exercessem uma autonomia e uma liberdade individual tão grandes, nem jamais o destino dessa sociedade esteve tão ligado aos comportamentos daqueles que a compõem.

Esta abordagem confere a devida importância para a cultura do colaboracionismo no design, ou seja, o codesign. Então caberá ao designer não apenas criar uma realidade artificial que poderá ser mais ou menos aceita pelos usuários, mas sim, projetar e apresentar claramente um cenário em que os próprios usuários possam desenvolver sua rede em busca de realizarem conjuntamente a realidade que agora percebem e desejam. Maneiras de articular a cartografia e a realidade em direção às projeções dos anseios, além de formas de interação possíveis e desejáveis para a transformação do ambiente das comunidades, poderão demandar a participação de outros agentes capacitados para uma diversidade tarefas que não poderíamos prever aqui, dado o rápido desenvolvimento tecnológico de nossos dias. A articulação de tais talentos se beneficiará, como vimos, de uma abordagem de design estra- 
tégico que se baseie no metadesign pela proposição dos cenários adequados e articulação dos múltiplos atores envolvidos.

O envolvimento do cidadão com acesso à internet nestas plataformas é de suma importância para o estabelecimento de um sistema de atores integrados. No entanto este benefício não é percebido ao público geral, o que sugere o desenvolvimento de novas funções de Design de Informação ou de usabilidade da plataforma, que atraiam as contrapartidas interessadas com os benefícios de divulgar o desenvolvimento local dos serviços e eventos culturais, no caso do mapeamento temático cultural. Esta divulgação pode ser vinculada em uma espécie de agenda urbana inicial com a disposição atualizada dos eventos a serem realizados bem como dos últimos eventos cadastrados.

\section{Referências}

ABRANCHES, Dra. Mônica. Controle social e planejamento urbano participativo: o mapeamento dos problemas da cidade pelos seus diversos atores. III Simpósio Mineiro de Assistentes Sociais, 2013. Disponível em: <http://www.cressmg.org.br/arquivos/simposio/CONTROLE\%20SOCIAL\%20E\%20PLANEJAMENTO\%20URB ANO $\% 20$ PARTICIPATIVO $\% 200 \% 20 M A P E A M E N T O \% 20 D O S \% 20 P R O B L E M A S \% 20 D A \% 2$ OCIDADE\%20PELOS\%20SEUS\%20DIVERSOS.pdf>.

BARAN, P. On Distributed Communications: introduction to distributed communications networks. Santa Monica: The Rand Corparation, 1964.

BEST, K. Design Management: Managing Design Strategy, Process and Implementation. Switzerland: AVA, 2006

BRUNEL, Felipe Kanarek. O design estratégico em nível metaprojetual como suporte para a inovação social: o caso slow food. p. 202-210 . In: Anais do $5^{\circ}$ Simpósio Brasileiro de Design Sustentável. São Paulo: Blucher, 2016. Disponível em:

$<$ http://pdf.blucher.com.br.s3-sa-east-

1.amazonaws.com/designproceedings/sbds15/2st701b.pdf>. Acessado em:

BHFAZCULTURA. Belo Horizonte, 2016. Disponível em: <http://www.bhfazcultura.pbh.gov.br/content/mapa-cultural-de-belo-horizonte>.

CASTELLS, Manuel. A era da intercomunicação. In Le Monde Diplomatique. Ago, 2006. Disponível em: <http://diplo.uol.com.br/2006-08,a1379>.

CASTELLS, M. A sociedade em rede. São Paulo: Paz e Terra, 1999.

DARODA, Raquel Ferreira. As novas tecnologias e o espaço público da cidade contemporânea. Dissertação Mestrado em Arquitetura na UFRGS. Porto Alegre, 2012. Disponível em: <http://www.ufrgs.br/propur/teses_dissertacoes/Raquel_daroda.pdf>. Acesso em: 20/05/2016.

DE MORAES, Dijon. Metaprojeto - o design do design. São Paulo: Ed. Blucher, 2010.

DELEUZE, Gilles, GUATTARI, Félix. Mil Platôs. Capitalismo e Esquizofrenia. Vol.1,Rio de Janeiro: Editora 34 Ltda, 1997.

EICHENBERG, Carolina Hermes; REYES, Paulo Edison Belo. Inovação social: arquitetura da rede ideia. 11 Congresso Brasileiro de Pesquisa e Desenvolvimento em Design, 2014. Disponível em: <http://www.proceedings.blucher.com.br/article-details/inovao-socialarquitetura-da-rede-ideia-12863>. Acesso em: 02/03/2017.

FERREIRA, Sônia De Souza; COUTINHO, Maura Neves; TEIXEIRA, Laura Fazito Resende Antunes; MOURA, Ana Clara Mourão. Abordagem metodológica de análises espaciais aplicadas ao ensino de cartografia para as ciências ambientais. Instituto de Geociências departamento de Geografia. XXIII Congresso Brasileiro de Cartografia, Rio de Janeiro, Brasil, 21 a 24 de outubro de 2007. Disponível em:

<https://www.researchgate.net/publication/268417809_abordagem_metodologica_de_analis 
es_espaciais_aplicadas_ao_ensino_de_cartografia_para_as_ciencias_ambientais>. Acessado em: 10/12/2016.

FMC. A Fundação Municipal de Cultura. Mapa Cultural de BH. Belo Horizonte, 2016. Disponível em: <http://www.bhfazcultura.pbh.gov.br/content/mapacultural-de-belo-horizonte>.

FRANZATO, Carlo; O princípio de deslocamento na base do metadesign, p. 1187-1195. In: Anais do $11^{\circ}$ Congresso Brasileiro de Pesquisa e Desenvolvimento em Design [= Blucher Design Proceedings, v. 1, n. 4]. São Paulo: Blucher, 2014.

GIACCARDI, Elisa. Metadesign as an Emergent Design Culture. Leonardo, v. 38, n. 4, 2005, p. 342-349. Disponível em: http://trans-techresearch.net/wpcontent/uploads/2012/03/giaccardielisa.pdf>.

IBGE - Instituto Brasileiro de Geografia e Estatística, Ministério do Planejamento, Orçamento e Gestão, Pesquisa de Informações Básicas Municipais - Perfil dos Municípios Brasileiros 2012

KRIPPENDORFF, Klaus. The semantic turn: a new foundation for design. Taylo \& Francis, 2006.

LASTRES, Helena Maria Martins; ALBAGLI, Sarita; LEMOS, Cristina; LEGEY, Liz-Rejane. Desafios e oportunidades da era do conhecimento. São Paulo Em Perspectiva, 16(3): 60-66, 2002. Disponível em: <http://www.scielo.br/pdf/spp/v16n3/13562.pdf>. Acessado em:

LIPOVETSKY, Gilles. Os tempos hipermodernos. São Paulo: BARCAROLLA, 2004.

MAGALHÃES, Cláudio. Design Estratégico: integração e ação do Design. Estudos em Design, v.3, n.1, jul. 1995.

MAURI, F. Progettare progettando strategia: il design del sistema prodotto. Milano, Dunod. 1996

MANZINI, Ezio; VEZZOLI, Carlo. O desenvolvimento de produtos sustentáveis: os requisitos ambientais dos produtos industriais. São Paulo: EDUSP, 2002. 366 p.

MANZINI, Ezio. Strategic Design for Sustainability: instruments for radically oriented innovation. In: JÉGOU, F; MANZINI, E. Sustainably everyday: scenarios of urban life. Milano: Edizioni Ambiente, 2003

Enzio. Design para inovação social e sustentabilidade: comunidades criativas, organizações colaborativas e novas redes projetuais. Editora E-Papers, Rio de Janeiro, 2008. Disponível em: <http://www.epapers.com.br/produtos.asp?codigo produto $=1494>$.

, Ezio. Design, when everybody designs: an introduction to design for social innovation. Cambridge: MIT Press Book, 2015. 241p. MANZINI, Ezio. Making Things Happen: Social Innovation and Design. Design Issues: v.30 n.1, 2014

MARTINHO, Cássio. Redes - Uma introdução às dinâmicas da conectividade e da auto-organização. Edição 1 - WWF - Brasil. Brasília, 2013. Disponível em: <http://www.dominiopublico.gov.br/download/texto/et000023.pdf>. Acessado em:

CULTURARJ Disponível em: <http://www.cultura.rj.gov.br/curso-gestoresagentes/textos/redesmidiasdig.pdf>.

MORIN, Edgar. A cabeça bem-feita: repensar a reforma, reformar o pensamento. Trad.: Eloá Jacobina. 7a ed. Rio de Janeiro: Bertrand Brasil, 2002b.

MERONI, A. 2008. Strategic design to take care of the territory. Networking Creative Communities to link people and places in scenario of sustainable development. In: CONGRESSO BRASILEIRO DE PESQUISA E DESENVOLVIMENTO EM DESIGN, 8, São Paulo. Anais. São Paulo, 2008. 1:31-38. 
MOURA. A. C. M. Estudo Metodológico de aplicação da cartografia temática às análises urbanas. IGC/UFMG. Brasil, Minas Gerais, Belo Horizonte, 1993. Dissertação de (Mestrado) da Universidade Federal de Minas Gerais.

NASCIMENTO, Fernando Pacheco Do. Mapas colaborativos e o espaço público [manuscrito]: a utilização de sistemas de mapeamento colaborativo online como ferramenta nos processos de requalificação urbana. Dissertacão (Mestrado em Arquitetura) Universidade Federal de Minas Gerais. Belo Horizonte, 2015.

OLIVEIRA, Isabel Cristina d'Avila. As redes sociais e a mobilização: espaço para o design. 5 Simposio de design sustentável, 2015. Disponível em:

$<$ http://www.proceedings.blucher.com.br/article-details/as-redes-sociais-e-a-mobilizaoespao-para-o-design-22517>. Acessado em:

PORTALBH. Comunidade Virtual da PRODABEL. Disponível em:

$<$ http://portalpbh.pbh.gov.br/pbh/ecp/comunidade.do?evento=portlet\&pldPIc=ecpTaxonomia MenuPortal\&app=prodabel\&lang $=p t \quad B R \& p g=5583 \&$ tax $=9122>$.

SAMPAIO, Rafael Cardoso; MAIA, Rousiley Celi Moreira; MARQUES, Paulo Jamil Almeida. Participação e deliberação na internet: Um estudo de caso do Orçamento Participativo Digital de Belo Horizonte. OPINIÃO PÚBLICA, Campinas, vol. 16, $n^{\circ} 2$, Novembro, 2010, p.446-477. Disponível em: <http://www.scielo.br/pdf/op/v16n2/a07v16n2>.

SILVA, Camila Di Cezar E. Pereira; ANDRADE, Dr. Vinicius. Mapa Digital Como Nova Linguagem Midiática. Terceiro Seminário de Iniciação Científica ESPM. São Paulo, 2014.

SILVA, Luan Carlos Santos; OLIVEIRA, Lindomar Subtil de; ZIBETTI, Júlio Henrique Ely; FACÓ, Renata Tilemann; PAULA, Istefani Carísio de; ECHEVESTE, Marcia Elisa Soares; CATEN, Carla Schwengber ten. Análise do plano de ação para produção e do consumo sustentável do Brasil. ISSN: 2237-0722 Revista GEINTEC - Gestão, Inovação e Tecnologias, v. 5, n3. São Cristóvão - Sergipe, 2015.

SANTOS, Clair Fatima Da Silva; TASCHETTO, Onildes Maria. Influência da instrumentalização metodológica no ensino de Clências. Orientação de outra natureza. PDE- Programa de Desenvolvimento Educacional) - Universidade Estadual do Oeste do Paraná, Secretária de Estado da Educação. 2009 Disponível em:

<http://www.diaadiaeducacao.pr.gov.br/portals/pde/arquivos/1896-8.pdf>.

VEZZOLI, Carlo. System design for sustainability: theory, methods and tools for a sustainable "satisfaction-system" design. Milano, Italy: Maggioli Editore, 2007.

ZURLO, Francesco. Design strategico. In: XXI Secolo. Roma: Enciclopedia Treccani, 2010. v. 4, Gli spazi e le arti. 